\title{
Despertando Vocações Através da Capacitação em Tecnologia: Experiências com Alunas do Ensino Médio da ECI EEFM Professor Celestin Malzac
}

\author{
Giorgia O. Mattos ${ }^{1}$, Josilene A. Moreira ${ }^{1}$, Laura L. A. O. Campos $^{1}$, Luyza E. D. \\ Nascimento $^{1}$, Maria L. M. Calixto ${ }^{1}$, Vanessa G. L. Pessoa ${ }^{1}$, Tiago E. S. Araujo ${ }^{2}$ \\ ${ }^{1}$ Centro de Informática - Universidade Federal da Paraíba (UFPB) \\ Rua dos Escoteiros, s/n - Mangabeira - 58.055-000 - João Pessoa - PB - Brazil \\ ${ }^{2}$ Escola Cidadã Integral Estadual de Ensino Fundamental e Médio Professor Celestin \\ Malzac \\ Rua Profa. Maria Zenaide Brasilino - Conjunto Valentina Figueredo I - 58.063-300 - \\ João Pessoa - PB - Brazil. \\ \{giorgia, josilene\}@ci.ufpb.br, \\ \{llauracampos, l.uyzadn09, malu.mcalixto, tiagoemillio\}@gmail.com, \\ vanessalimalcc.ci.ufpb.br
}

\begin{abstract}
This work presents the initiatives developed with girls from the 1st year of high school at ECI EEFM Professor Celestin Malzac in the city of João Pessoa/PB during the year 2019. The initiatives included unplugged computing, a short course for developing mobile applications, in addition to lectures and debates about prominent female personalities as well as female insertion in technology. At the end of the activities, an evaluation questionnaire was applied where the data obtained are also presented, analyzed and discussed.
\end{abstract}

Resumo. Este trabalho apresenta as iniciativas desenvolvidas com alunas do $1^{\circ}$ ano do ensino médio da ECI EEFM Professor Celestin Malzac na cidade de João Pessoa/PB durante $o$ ano de 2019. As iniciativas incluíram a computação desplugada, minicurso de desenvolvimento de aplicativos para dispositivos móveis, além de palestras e debates sobre as personalidades femininas de destaque bem como a inserção feminina na tecnologia. Ao final das atividades foi aplicado um questionário de avaliação onde os dados obtidos são também apresentados, analisados e discutidos.

\section{Introdução}

Historicamente, as práticas sociais, dentre elas, as escolares, vêm contribuindo para a segregação por sexo. A história da educação das mulheres mostra que elas foram excluídas e a partir do século XIX começaram a ser inseridas progressivamente nas escolas, mas de maneira segregada [Carvalho e Rabay 2013].

Neste processo de inclusão das mulheres nas escolas elas foram impedidas e/ou desestimuladas a ingressarem em certas áreas do conhecimento e profissões que se mantiveram como espaços masculinos, segundo a visão de que matemática era para meninos, trabalhos manuais para meninas. Os fatores são diversos [Martins et al. 2019] [Moreira et al. 2018] e envolvem desde crenças sexistas de que as mulheres não 
possuem competências espaciais e matemáticas [Hill et al. 2010], passando pelo clima hostil do ambiente acadêmico [Cooper et al. 2010] e chegando aos estereótipos de gênero que reduzem a autoestima, a autoconfiança e a autoeficácia para o público feminino, uma vez que as tecnologias são, tradicionalmente, um campo de conhecimento e prática masculinos [Wajcman 2006]. Esta separação de homens e mulheres em diferentes campos do conhecimento reflete-se nas escolhas de cursos superiores. Dados divulgados pela Sociedade Brasileira de Computação [SBC 2018] apontaram que, em 2016, 13,66\% dos alunos ingressantes na computação eram meninas, contra a $86,34 \%$ de meninos. Com relação aos concluintes, as meninas totalizaram $15,48 \%$ contra $84,52 \%$ dos meninos. Na Universidade Federal da ParaíbaUFPB, nos cursos da área de Ciência da Computação, as mulheres são apenas $14 \%$ do total de estudantes, acompanhando a média nacional [STI 2019].

No Brasil existe várias iniciativas com o objetivo de mudar esse cenário a médio e longo prazo [Maciel e Bim 2016]. O grupo Meninas na Computação também é uma destas iniciativa e tem como principal objetivo atrair meninas do ensino básico para as carreiras de exatas, engenharia e computação tendo em vista os altos índices de desigualdade de gênero nestas áreas. $O$ grupo vem desenvolvendo atividades de pesquisa e extensão nesta temática [Mattos et al. 2018] [Moura et al. 2019].

Este relato descreve as atividades que foram desenvolvidas no segundo semestre de 2019 com alunas do $1^{\circ}$ ano do ensino médio na Escola Cidadã Integral Estadual de Ensino Fundamental e Médio - ECI EEFM Professor Celestin Malzac na cidade de João Pessoa/PB com o objetivo de mostrar a elas a presença feminina na área de tecnologia, personalidades femininas de destaque e a computação como uma possível carreira a ser seguida.

\section{Metodologia Adotada}

Esse trabalho foi construído por meio de um relato de experiência com a finalidade de apresentar métodos que possibilitaram estimular o ensino da computação através do incentivo a alunas na evolução do pensamento lógico através da introdução à computação. Além disso, foram trabalhadas temáticas cotidianas acerca da desigualdade de gênero no campo do trabalho e aplicados desafios na computação propiciando avanços no processo de ensino-aprendizagem e na influência à carreira na área.

A experiência aqui relatada foi realizada em uma escola da rede pública estadual com um grupo de alunas do 10 ano do Ensino Médio. As atividades aconteceram quinzenalmente às sextas-feiras pela manhã, no período de agosto a novembro de 2019 . Inicialmente houve uma reunião de planejamento participativo com a escola onde foram apresentados o projeto, os conteúdos que seriam abordados e a metodologia adotada em sala de aula. Nessa reunião foi possível realizar um levantamento do perfil das estudantes, da disponibilidade de horários e as pretensões futuras, a fim de definir qual turma se encaixaria melhor à proposta. A escolha do grupo visou, principalmente, a possibilidade de dar continuidade ao acompanhamento das alunas durante os três anos regulares do Ensino Médio.

Durante o primeiro contato com as estudantes, foi realizada uma palestra introdutória para apresentação do projeto, exposição do conteúdo programático e a dinâmica das aulas. Foi aplicado um questionário de diagnóstico do perfil das estudantes. Nesse encontro também foi realizado um debate acerca de profissões e do 
estereótipo da participação de mulheres em determinadas áreas de atuação. $\mathrm{Na}$ ocasião, as alunas puderam expor o seu pensamento a respeito do tema além de indicar se possuíam algum conhecimento prévio, interesse ou prejulgamento sobre a Ciência da Computação.

Nos encontros seguintes também foram realizadas palestras sobre a importância da participação das mulheres na ciência ao longo da história, onde as alunas tiveram a oportunidade de conhecer grandes nomes por trás de projetos relacionados à Matemática, Física, Química e Computação. Nessa prática, as alunas participantes foram capazes de desenvolver, de forma escrita, um quiz (teste) a respeito de grandes pesquisadoras femininas e seus feitos. $\mathrm{O}$ quiz foi implementado computacionalmente em atividades seguintes.

Os conteúdos técnicos abordados foram os relacionados à introdução à lógica de programação, como a definição dos conceitos de algoritmos, funções, condicionais e operadores lógicos. A escola estava passando por uma reforma e seu laboratório de informática não esteve disponível durante todo o segundo semestre de 2019, assim as atividades relacionadas ao tema foram desenvolvidas através da Computação Desplugada. O termo, proveniente do inglês Computer Science Unplugged, é um método de ensino com o objetivo de explicar os fundamentos da computação sem a necessidade do computador [Bell et al., 2009].

A Tabela 1 apresenta as atividades realizadas, assim como o conteúdo de computação relacionado e os materiais necessários para a sua realização. Os exercícios propostos, nessas aulas, foram baseados em dinâmicas presentes na plataforma Code Studio (http://www.code.org) e adaptados pelos autores de acordo com os recursos disponíveis e as necessidades da turma. As atividades que tinham como objetivo o desenvolvimento da lógica computacional foram desenvolvidas de forma lúdica, com o intuito de despertar ou intensificar o interesse das alunas por conteúdos relacionados à computação.

Tabela 1 - Atividade propostas, conteúdo técnico abordado e materiais necessários

\begin{tabular}{|c|c|l|}
\hline Atividade & Conteúdo relacionado & \multicolumn{1}{|c|}{ Materiais utilizados } \\
\hline $\begin{array}{c}\text { Lightbot } \\
\text { Humano }\end{array}$ & Algoritmos & $\begin{array}{l}\text { Fita adesiva para montagem do } \\
\text { percurso no chão }\end{array}$ \\
\hline $\begin{array}{c}\text { Identificação } \\
\text { de Padrões }\end{array}$ & Funções & $\begin{array}{l}\text { Caixa de som para reprodução da } \\
\text { canção e ficha impressa para o } \\
\text { preenchimento pelas alunas }\end{array}$ \\
\hline $\begin{array}{c}\text { Condicionais } \\
\text { com Cartões }\end{array}$ & $\begin{array}{c}\text { Condicionais (se, senão, } \\
\text { senão se) e operadores lógicos } \\
\text { (e, ou, não) }\end{array}$ & $\begin{array}{l}\text { Cartas numeradas de 0 a 9 e fichas } \\
\text { contendo situações para as } \\
\text { condicionais }\end{array}$ \\
\hline
\end{tabular}

A dinâmica "Lightbot Humano" consistiu em reproduzir a ideia da plataforma Lightbot (http://www.lightbot.com), na qual o programador deve ser capaz de fazer com que o robô chegue ao destino indicado apenas com comandos de "um passo à frente", "vire à esquerda" ou "vire à direita". Na situação em questão, uma aluna, que estava vendada, seria o robô e as demais seriam as programadoras que descreveriam o 
algoritmo para que a personagem chegasse ao objetivo final. A atividade teve como objetivo ensinar o conceito de algoritmos e usou como materiais apenas uma fita adesiva, para demarcar o caminho que deveria ser seguido pela aluna, e a venda para que esta chegasse ao destino apenas com os comandos das colegas.

A prática "Identificação de Padrões", dividida em duas etapas, consistiu em apresentar músicas para as alunas como analogia às funções. A primeira música escolhida "Numa Sala de Reboco" do compositor nordestino Luiz Gonzaga, foi escrita como um código, no qual o refrão foi apresentado apenas uma vez e chamado como uma função em seguida. A missão das alunas era identificar qual a parte do código em que a função seria chamada e, nesse momento, cantar o refrão da música. A segunda etapa trabalhou o conceito de passagem de parâmetros. Foi escolhida a música "Sabiá", do mesmo compositor, por possuir um refrão com palavras que se repetem algumas vezes. Estas, por sua vez, seriam as variáveis, que poderiam ser substituídas pelos parâmetros que foram passados. $\mathrm{Na}$ música original, as variáveis repetidas eram representadas pelas palavras "sabiá" e "psiu" e poderiam ser trocadas por parâmetros como "gato" e "miau", quando solicitado. As alunas receberam um formulário impresso para o preenchimento da atividade. O objetivo desse exercício foi ensinar conceitos de funções e a prática da passagem de parâmetros. Os materiais utilizados foram uma caixa de som para reprodução das canções e uma ficha impressa para a segunda etapa.

A atividade "Condicionais com Cartão" consistiu em um jogo de cartas onde as alunas foram divididas em grupos com cinco participantes e cada grupo recebeu um conjunto de cartas coloridas, numeradas de 0 a 9 , que deveriam permanecer viradas para baixo, sem que as alunas pudessem ver o conteúdo. Na frente da turma eram puxadas fichas contendo um trecho de código, utilizando condicionais e operadores lógicos, que indicavam as pontuações. A cada rodada uma ficha era mostrada e o grupo puxava a carta de cima do monte, apresentava o número para a turma e explicava se pontuou ou não e o porquê, de acordo com o comando apresentado no código e em como o número da carta se comportaria em tal condição. A atividade teve como objetivo ensinar os conceitos de condicionais (se, senão, senão se) e operadores lógicos (e, ou, não). Os materiais utilizados foram os cartões, com os trechos de código apresentados à turma, e um baralho apenas numérico.

As imagens apresentadas na figura 1 mostram alguns momentos da realização da dinâmica Lightbot Humano.
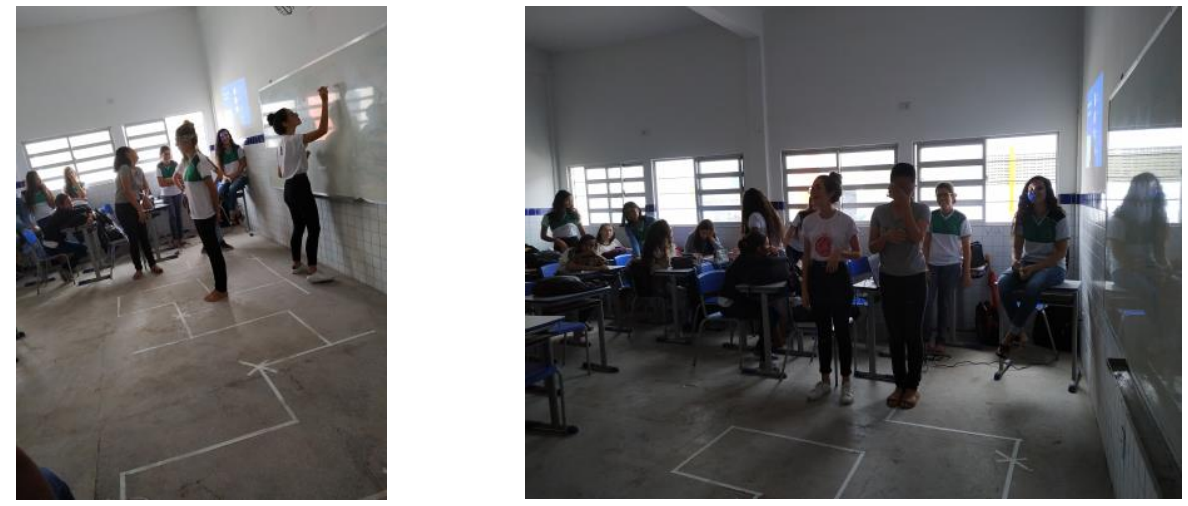

Figura 1 - Atividade Lightbot Humano. 
A última etapa do projeto foi destinada ao desenvolvimento de um aplicativo através da plataforma MIT App Inventor (https://appinventor.mit.edu/). A aplicação escolhida para essa atividade foi o quiz (teste) sobre mulheres importantes para a ciência, desenvolvido de forma textual em encontros anteriores. A oficina aconteceu em um laboratório do Centro de Informática da UFPB e foi dividida em dois encontros. A figura 2 mostra imagens do encontro.
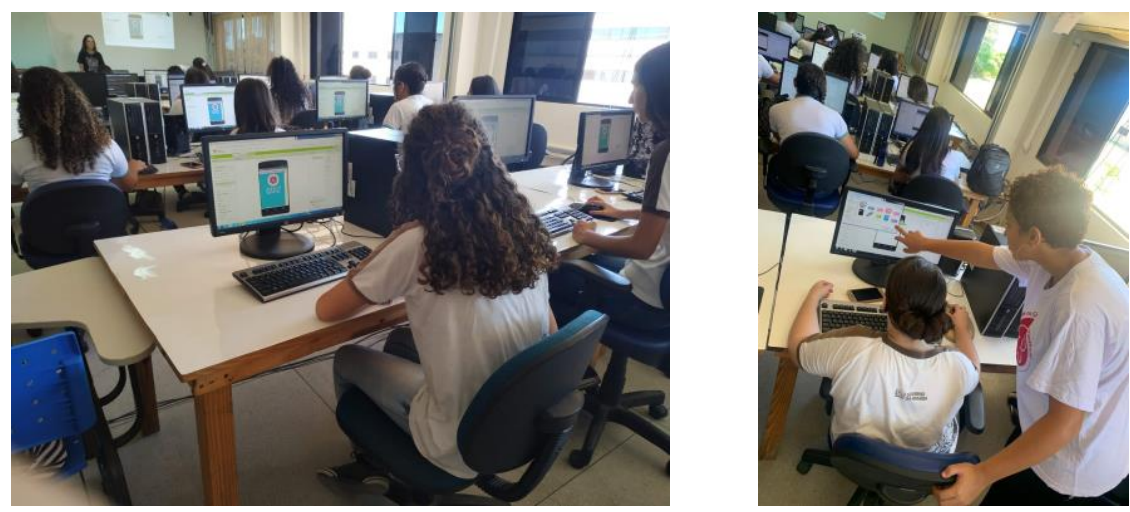

Figura 2 - Atividade prática de desenvolvimento do aplicativo Quiz.

No primeiro encontro foi feito um reconhecimento geral da ferramenta e suas funcionalidades, assim como o cadastro das alunas na plataforma. Esse encontro foi dedicado à criação da interface do quiz e, conforme os comandos eram apresentados, cada aluna tinha a possibilidade de desenvolver e criar o seu próprio aplicativo. No segundo encontro foi elaborado o código, através da programação em blocos, para descrever o funcionamento da aplicação. Nessa etapa as alunas tiveram a oportunidade de aplicar os conceitos de criação de algoritmo e utilização de funções, condicionais e operadores lógicos, abordados nas dinâmicas de computação desplugada. Ao fim do processo de codificação, cada participante pôde carregar o aplicativo desenvolvido para o seu próprio smartphone.

\section{Resultados e Discussões}

Ao todo 25 alunas do $1^{\circ}$ ano do ensino médio participaram das atividades propostas no segundo semestre do ano de 2019, ficando 23 delas até o final das atividades. No início dos trabalhos foi aplicado um questionário com questões de cunho geral para identificar o perfil das alunas e orientar a equipe na condução das atividades.

$\mathrm{Na}$ figura 3 são mostrados alguns resultados julgados importantes para a orientação das atividades a serem desenvolvidas com as alunas da escola. O primeiro gráfico da figura, segundo as alunas, mostra que a preferência delas são por disciplinas das áreas de humanas e biológicas e as que tem mais dificuldades são as da área de exatas, principalmente matemática e física. Todas elas disseram ainda usar o celular diariamente e $80 \%$ não usam computadores com frequência. Todas elas também utilizam a internet diariamente principalmente para acessar as redes sociais, escutar música e fazer pesquisas para trabalhos escolares. Os outros dois gráficos mostram as áreas de escolhas profissionais apontadas pelas alunas, sendo a área da Saúde a que aparece com maior frequência. Alguns cursos citados foram Medicina, Psicologia, Fisioterapia e Enfermagem. Somente 4\% delas disseram não saber ainda qual curso escolher. Quando perguntado a elas sobre a possibilidade de escolher um curso na área 
de Computação, 52\% disseram que não escolheriam. Os principais motivos apontados foram a falta de conhecimento da área, o fato de não gostarem de matemática e préjulgarem que cursos da área de computação são muito difíceis.
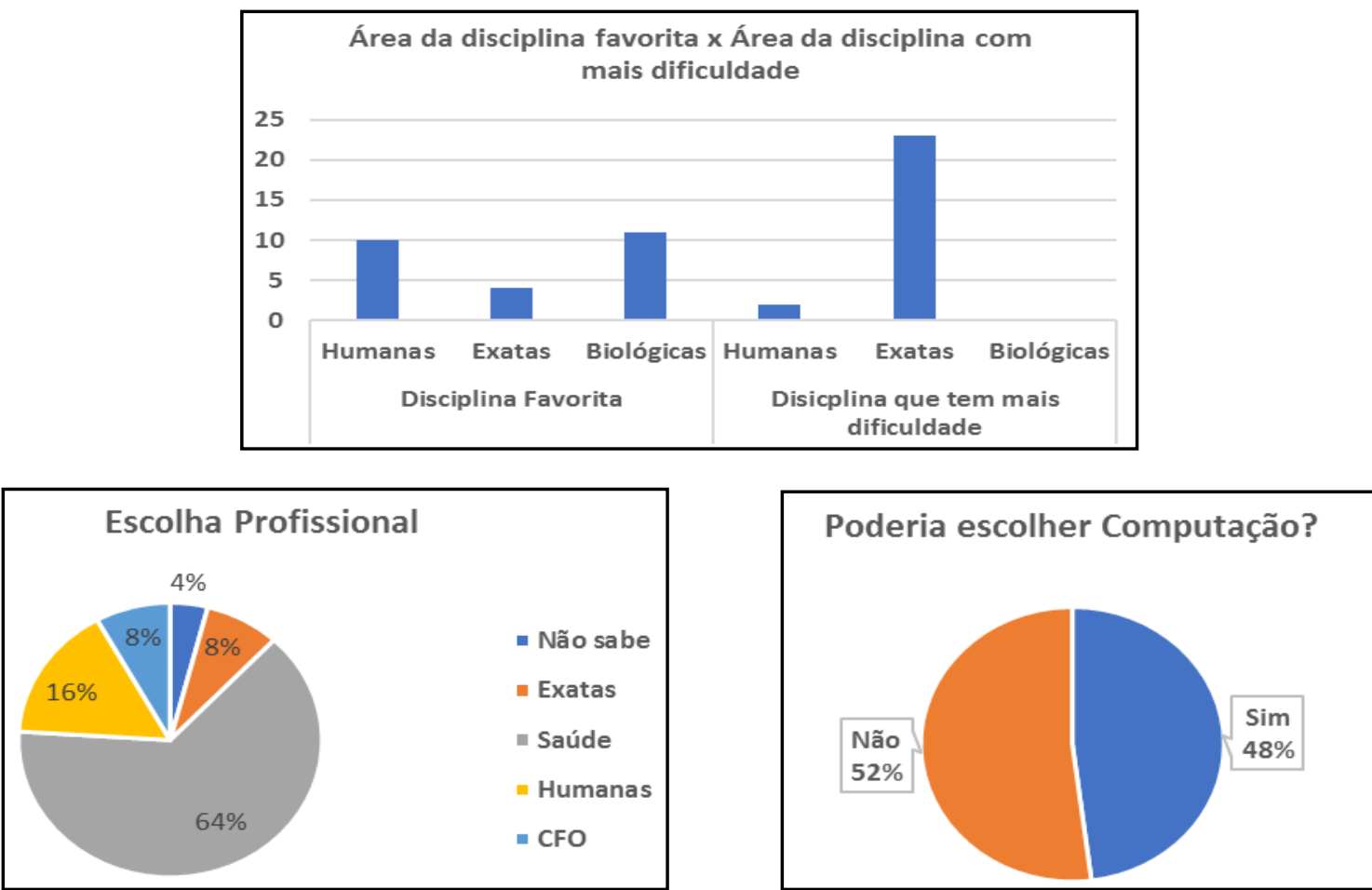

Figura 3 - Alguns resultados considerados importantes que nortearam a definição das atividades desenvolvidas

Ao término das atividades também foi elaborado um questionário de avaliação das atividades propostas sendo que ao todo 16 alunas responderam. O objetivo do questionário foi avaliar o grau de satisfação/motivação das alunas, o conhecimento prévio delas sobre assuntos da área, o quão difícil foram as atividades propostas e o nível de satisfação com a sua participação. Os resultados consolidados estão apresentados na figura 4 e figura 5. Segundo as alunas, $81 \%$ estavam muito interessadas e motivadas em participar das atividades e $87 \%$ não tinham nenhum conhecimento prévio sobre assuntos de computação, conforme representado na figura 4.

Motivação em participar das atividades

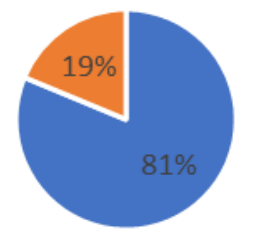

- Muito motivada - Pouco motivada

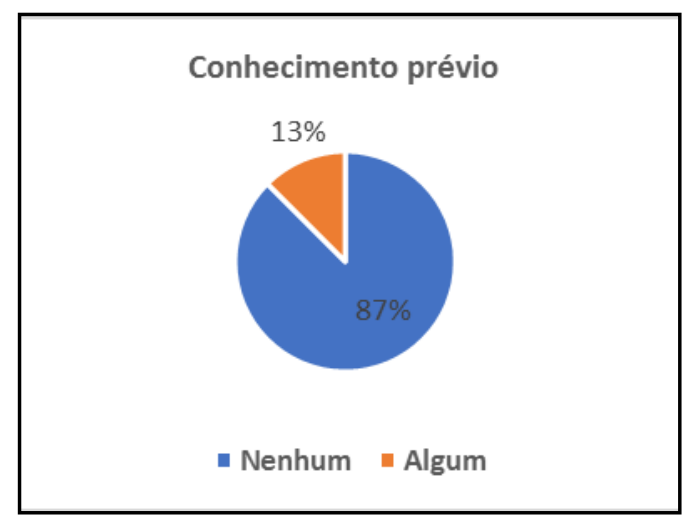

Figura 4 - Resultados obtidos considerando a motivação em participar das atividades e o conhecimento prévio em computação 
A figura 5 mostra alguns resultados em relação às atividades com a computação desplugada e o desenvolvimento de aplicativos com o App Inventor. Os resultados mostram que no geral as alunas gostaram muito das atividades propostas, considerandoas divertidas, e com relação à dificuldade consideraram-na um pouco difícil. Com relação à atividade de desenvolvimento de aplicativos $81 \%$ das alunas gostaram da atividade, $6 \%$ delas gostaram, mas acharam cansativa e 13\% não gostaram. Sobre a dificuldade nessa atividade, a maioria julgou um pouco difícil.
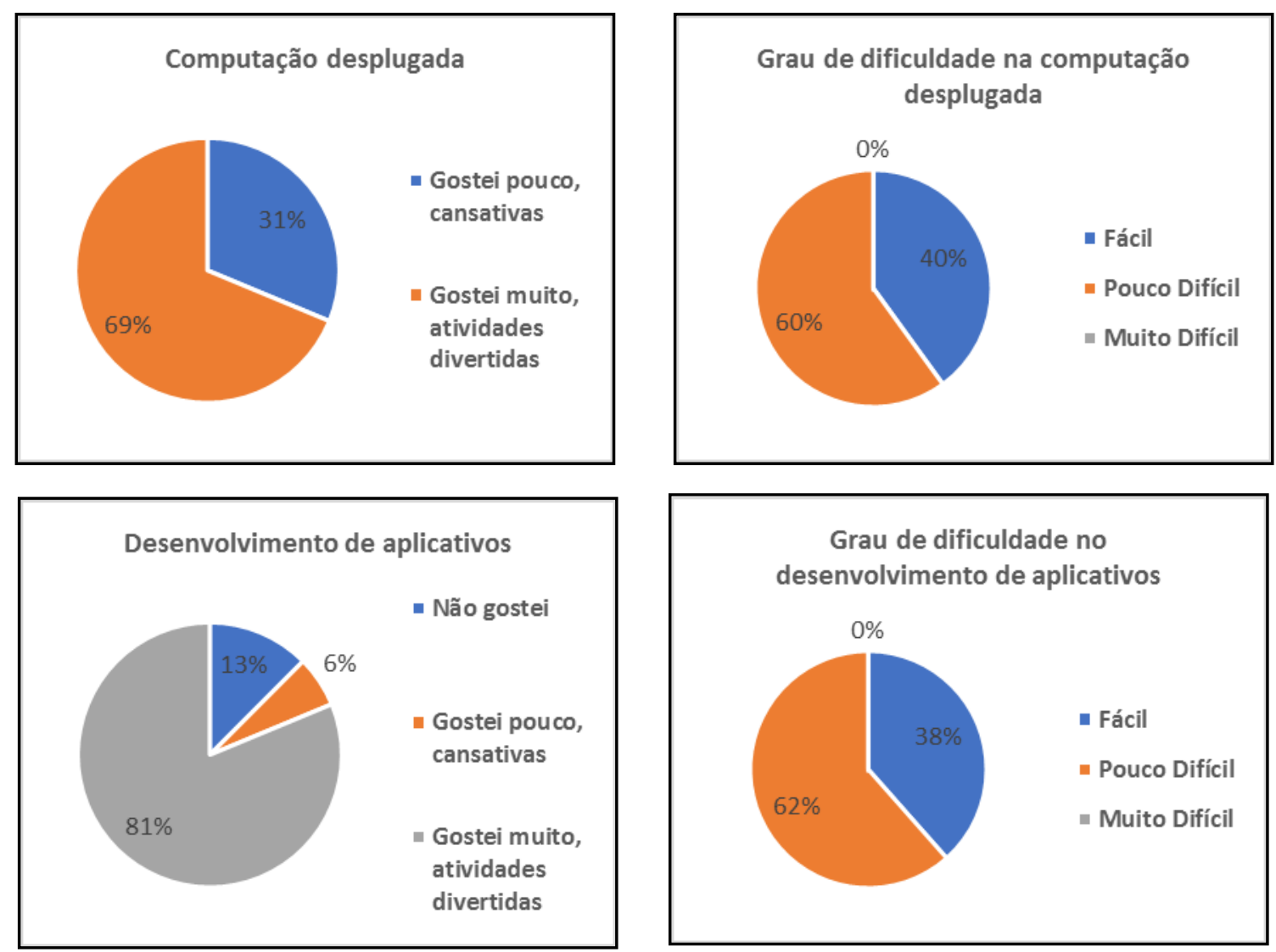

\section{Figura 5 - Resultados obtidos considerando as atividades de computação desplugada e desenvolvimento de aplicativos}

De maneira geral as alunas se sentiram motivadas e interessadas em participar das atividades especialmente do desenvolvimento do quiz onde puderam vivenciar na prática algumas etapas do processo de desenvolvimento além de testarem em seus próprios celulares um aplicativo desenvolvido por elas próprias.

\section{Conclusões}

Este trabalho descreveu as atividades realizadas durante o segundo semestre de 2019 com alunas do $1^{\circ}$ ano do ensino médio da ECI EEFM Professor Celestin Malzac na cidade de João Pessoa/PB. As atividades propostas tiveram como objetivo mostrar às alunas os cursos da área de computação oferecidos pela Universidade, tratar da problemática de gênero existente em carreiras da área tecnológica apresentando perfis femininos de destaque e treiná-las na área de computação sempre dialogando e mostrando a sua capacidade para lidar com a tecnologia. 
As atividades desenvolvidas foram baseadas no conceito de computação desplugada, aquelas realizadas sem a utilização do computador, e no desenvolvimento de aplicativos para dispositivos móveis com a ferramenta MIT App Inventor. As alunas relataram, através da aplicação de questionários, que se sentiram bastante motivadas e interessadas em participar das atividades, a maioria não achou difícil e demonstrou interesse de que as atividades continuassem em 2020. A atividade que mais despertou o interesse delas foi o desenvolvimento de aplicativos onde puderam implementar, na prática, um teste a respeito de uma personalidade feminina da área tecnológica.

Os objetivos pretendidos inicialmente com a ação foram cumpridos uma vez que foi mostrada a área de computação às alunas e deixou plantado em suas mentes a possibilidade de considerar a computação como uma futura escolha de carreira profissional. No ano de 2020 as ações continuarão com o grupo sempre tendo como objetivo contribuir para a mudança do cenário da participação feminina na área tecnológica, especialmente na computação.

\section{Referências}

Bell, T., Alexander, J., Freeman, I. and Grimley, M. 2009. "Computer Science Unplugged: School Students Doing Real Computing Without Computers". New Zealand J of Applied Computing and Information Technology, 13(1), 20-29.

Carvalho, M. E.; Rabay, G. (2013) Gênero e Educação Superior: Apontamentos Sobre o Tema. João Pessoa: Editora da UFPB, 2013.

Cooper, J., Eddy, P., Hart, J., Lester, J., Lukas, S., Eudey, B., Glazer-Raymo, J., Madden, M. (2010). Improving Gender Equity in Postsecondary Education. Handbook for Achieving Gender Equity Through Education 2 ed., p. 631-653. New York and London: Routledge.

Hill, C., Corbett, C. e St. Rose, A. (2010). Why so Few? Women in Science, Technology, Engineering, and Mathematics. AAUW, Washington DC.

Maciel,C., Bim, S. A. (2016) "Programa Meninas Digitais - Ações para divulgar a computação para meninas do ensino médio", In: Computer on the Beach, 2016, Itajaí - SC. Anais do Computer on the Beach 2016 e recurso eletrônico, 2016. p. 327-336.

Martins, A., Silva, J. D., Santos, J., Dantas, A. (2019). Fatores que Atraem e Afastam as Meninas de Cursos da Área de TI. In: Anais do $13^{\circ}$ Women in Information Technology (WIT2019). SBC, 2019.

Mattos, G. O., Moreira, J. A., Moura, A. F. S. A., Nascimento, A. B., Oliveira, C. O. (2018). Oficinas de Programação para Meninas: Despertando o Interesse Pela Computação. In: Anais do $26^{\circ}$ Workshop Sobre Educação em Computação (WEI2018). SBC, 2018.

Moreira, J. A., Mattos, G. O., Moreira, G. A.; Oliveira, C. C., Nascimento, A. B., Moura, A. F. S. A., Sousa, S. A. (2018). Barreiras que Impedem a Opção das Meninas pelas Ciências Exatas e Computação: Percepção de Alunas do Ensino Médio. In: Anais do $12^{\circ}$ Women in Information Technology (WIT2018). SBC, 2018.

Moura, A. F. S. A, Tavares, T. H. C., Moreira, J. A., Silva, R. M., Mattos, G. O. (2019). Virtualização de questões da OBI para o desenvolvimento do pensamento 
computacional. In: Anais dos Workshops do VIII Congresso Brasileiro de Informática na Educação (WCBIE 2019).

SBC. Sociedade Brasileira de Computação. Educação Superior em Computação Estatísticas - 2016. Disponível em: <http://sbc.org.br/documentos-dasbc/summary/133-estatisticas/1167-educacao-superior-em-computacao-estatisticas2016>.

STI - Superintendência de Tecnologia da Informação, (2019). Universidade Federal da Paraíba.

Wajcman, J. (2006) El Tecno Feminismo. Madrid: Ediciones Cátedra, 2006. (Colección Feminismos). 